\title{
Horizontes y problemas del audiovisual andaluz
}

\author{
Dr. Francisco Sierra Caballero \\ Profesor Asociado de Teoría de la Información. \\ Director del Seminario de Estudios Europeos en Comunicación. \\ Departamento de Periodismo. \\ Facultad de Ciencias de la Información. Universidad de Sevilla. \\ fsierra@cica.es
}

\section{RESUMEN}

Hoy no es posible distinguir en el campo de la cultura, esto es, en el mercado, entre producción cinematográfica y producción audiovisual. Más allá del matrimonio del sistema radiotelevisivo y la industria del cine, el audiovisual y las redes multimedia de los operadores de telecomunicación son el medio de desarrollo que atraviesa el modo y las formas de producción cinematográfica, bajo el control de los grupos oligopólicos de la industria de la cultura. El espectáculo cinematográfico no se organiza pues en torno a la capacidad de producción, sino por la presencia en el mercado, por la integración en los sistemas de difusión y canalización audiovisual, en la intersección de lo económico y lo cultural. Como sabemos, estas redes de distribución y difusión audiovisual están atravesadas históricamente por relaciones de poder internacional, a nivel económico, que condicionan el consumo y orientación del mercado cinematográfico.

\section{ABSTRACT}

Today, it is not possible to distinguish in culture market between film production and audiovisual production. Audiovisual system and multimedia nets of telecommunication operators are the mean of development that crosses the way and the forms of film production, under the control of the oligopoly groups in cultural industry. In this way, film show is not organized around production capacity, but for its presence in market, in the intersection of the economic and the cultural issue. This article analyses how audiovisual distribution and difussion nets are crossed by international power relationships that are an important point in the consumption and orientation of film market.

Palabras claves: Economía política/Desarrollo de medios/Cultura global/Estudios cinematográficos/Desarrollo local.

Key Words: Political economy/Media development/Global culture/Cinema studies/Local development.

as principales distribuidoras vinculadas a las majors americanas (Hispa no-Fox, Lauren Films, Columbia Tri-Star, Warner Española y United International Pictures) controlan cerca de dos tercios del total de los ingresos anuales por taquilla: 
«El resultado final es un sector oligopolístico en el que estas últimas controlan los canales de distribución, se aseguran las mejores salas, fechas y condiciones de exhibición, desplazando al cine español e incluso extienden sus redes por otros canales de comercialización como la televisión y el video. Mientras, el espacio de los distribuidores independientes españoles, los que deben canalizar la mayor parte de nuestra producción, es cada vez más pequeño» ${ }^{(l)}$.

El éxito internacional, y entre el público español, de las películas exhibidas desde 98 contrastan con los datos oficiales que muestran una tendencia a la baja de la participación en el mercado audiovisual, progresivamente concentrado por un cada vez menor número de productores desde los años ochenta.

La definición del cine español como «políticamente ineficaz, socialmente falso, intelectualmente ínfimo, estéticamente nulo e industrialmente raquítico» ha sido en parte superada. Ahora bien, aunque el cine español experimenta una mejoría económica, el cine norteamericano controla ampliamente nuestro mercado. El espacio audiovisual en España sigue concentrado por los productores estadounidenses, siendo nuestro país el séptimo importador de filmes norteamericanos en detrimento del resto de la Unión Europea, mientras Estados Unidos apenas importa en torno al uno por ciento de su programación cinematográfica de los países no anglosajones. La presión de los productores cinematográficos limita, por otra parte, cualquier intento de participación de las empresas locales que signifique una reducción del dominio estadounidense en la industria de menos del $70 \%$ de la programación audiovisual. Ciertamente, la producción cinematográfica nacional ha logrado proyectarse mundialmente en el mercado, pero a condición de una liberalización y desintegración cultural de la industria y los circuitos de valorización, progresivamente concentrados en todas sus formas por la industria norteamericana o, en ciertos casos, por empresas de procedencia europea.

La desaparición del monopolio estatal de televisión y la privatización del espacio público audiovisual a partir de los años ochenta ha condicionado de este modo, como en el resto de Europa, la comercialización de la filmografía nacional, en el interior y fuera del país.

El fortalecimiento público de la producción audiovisual ha sido cifrado en los avatares e intereses del mercado, renunciando a la creación de un verdadero y potente espacio audiovisual europeo. Como en Latinoamérica, el reconocimiento de una identidad regional autónoma ha sido finalmente neutralizado por las señas

1. V. Fernández Blanco, «El mercado cinematográfico español», en Letra Internacional, n58, Madrid, 1998, p.56. 
de identidad del imaginario espectacular que la «industria Hollywood» monopoliza, de facto $^{(2)}$.

\section{EUROPA VS. ESTADOS UNIDOS}

El futuro de la producción cinematográfica en Europa, como parte de la política de construcción de la sociedad informacional comunitaria, ha quedado a merced de las coyunturas e intereses económicos de la industria multimedia con el cambio de orientación en la política cultural de la Unión Europea.

A partir de 1993, y especialmente en los dos últimos años, la primacía económica en las decisiones de la Comisión ha impuesto una visión industrial liberalizadora frente a los tímidos intentos de la Directiva Televisión sin Fronteras o el insuficiente impulso de programas como MEDIA, que deja en manos del dominio estadounidense el desarrollo del más importante mercado audiovisual del mundo.

A partir de la derrota política en las negociaciones de la Ronda Uruguay del GATT que validaba la liberalización general de la industria de la información, frente a la reivindicación del criterio de «excepcionalidad cultural» abanderada por Francia, la Unión Europea ha asumido como propio el objetivo político de la competitividad y la convergencia económica en torno a los procesos de expansión y concentración industrial del sector de las telecomunicaciones:

«El informe sobre la sociedad de la información y el libro verde sobre la industria de programas fueron los primeros cimientos. En segundo lugar, la revisión de la directiva Televisión sin Fronteras y la aprobación de la segunda edición del programa MEDIA, ambos ejes fundamentales de la actuación comunitaria, fueron un paso más hacia una lógica primacía económico-industrial. Posteriormente, se han elaborado nuevos informes (convergencia de las telecomunicaciones, informática y los medios de comunicación; prospectiva de los mercados audiovisuales en Europa, etc...) en esta misma línea. Todos estos documentos y actuaciones han ido dibujando la imagen de conjunto del audiovisual europeo, poniendo sobre la mesa un nuevo modelo de política audiovisual a nivel de la Unión» ${ }^{(3)}$.

2. Cfr. Jesús Martín Barbero, De los medios a las mediaciones, Gustavo Gili, México, 1987, pp.164-206. 
La nueva política de la información en la Comunidad Europea tiene por objetivos prioritarios:

- Crear una industria europea fuerte.

- Sentar las bases de un fuerte y competitivo mercado interno.

- Y mejorar la productividad.

Distintos informes de la Comisión han subrayado la preocupante ausencia de redes de distribución continentales en el sector, y de una consolidada industria audiovisual que compita libremente en el mercado con los conglomerados multimedia estadounidenses. En respuesta a estas y otras muchas debilidades de la industria europea, la nueva política audiovisual comunitaria ha propuesto una política de liberalización y mejora económica del sector, en función del desarrollo de las libres fuerzas del mercado, la inversión en medios de distribución adecuados y el apoyo público, y financiero, a la formación y desarrollo del talento creativo de los profesionales del audiovisual.

Esta política informativa no toma sin embargo en cuenta los efectos que se derivan de tal marco ideológico en la estructura del sistema audiovisual europeo. El liberalismo en regiones como Andalucía o en industrias audiovisuales de estados, como el español, caracterizadas por la escasa o nula implantación productiva, y menos aún por lo que se refiere a la capacidad de distribución y exhibición cinematográficas, está favoreciendo de este modo un claro reforzamiento de las posiciones económicas norteamericanas. En este sentido:

$1^{\circ}$ ) El Libro Verde sobre la industria de producción audiovisual en Europa no toma en cuenta el riesgo de ver la diversidad de programas y la libertad de expresión sometida al monopolio de los operadores de telecomunicaciones en el mercado internacional.

$2^{\circ}$ ) La influencia y los intereses divergentes de los grupos mediáticos no contemplan que el actual modelo económico de expansión industrial garantice un desarrollo equilibrado del espacio audiovisual en el interior de la Comunidad Europea.

$3^{\circ}$ ) La identidad cultural queda, en definitiva, desplazada por la economía política de la comunicación.

La revisión de la directiva Televisión sin Fronteras y la insuficiencia de programas comunitarios como MEDIA, hacen por lo mismo previsible en el

3. Carmina Crusafon, «El nuevo enfoque de la política audiovisual de la Unión Europea (1994-1998): la primacía de la dimensión económico-industrial», en Ambitos. Revista Andaluza de Comunicación, $\mathrm{n}^{\circ} 1$, Sevilla, 1998, p. 74. 
contexto de convergencia y desregulación de las telecomunicaciones, una progresiva profundización del gran déficit existente desde 1994 en el balance comercial con Estados Unidos en el sector audiovisual.

La «narrativa hollywoodense» como programa hegemónico de centralización y gestión de los fragmentados mercados nacionales que integran la Unión Europea va a ser, por tanto, el vínculo de cohesión del audiovisual comunitario, acentuando previsiblemente el bajo nivel de circulación y distribución transfronteriza de películas europeas en el interior de la propia Comunidad.

Los nuevos imperios audiovisuales, la creciente monopolización de las redes y circuitos de valorización de las industrias audiovisuales y el control del poder de organización de la descentralización económica por el capital transnacional descansa hoy en las hibridaciones culturales que promueven las nuevas empresas multimedia de capital norteamericano. Disney, Twentieth Centry Fox, MCA/ Universal, Paramount, Columbia y Warner Bros son las empresas artífices de una lógica económico-política del audiovisual al servicio de los intereses estratégicos de importantes operadores multimedia como FOX, Viacom, Sony o Time Warner. Estos, y no otros, están siendo, en verdad, los verdaderos constructores de la identidad europea, los agentes de unificación e integración del mercado audiovisual comunitario.

Desde hace años, las grandes productoras estadounidenses han adquirido una importante ventaja al poder distribuir sus cintas por todo el mundo sin gastos excesivos por medio de los nuevos canales de distribución y programación vía satélite, cable y plataformas digitales, espacio este último que la Directiva Televisión sin Fronteras quería regular de cara al desarrollo de la industria audiovisual europea. Hoy, sin embargo, «las economías de escala permiten que Hollywood venda decenas de películas, amortice presupuestos multimillonarios y financie una red mundial de oficinas, todo lo cual reduce los costos de distribución de cada película por debajo del desembolso que realizan sus competidores» ${ }^{(4)}$, en detrimento de nuestra producción cinematográfica local.

\section{LA LOGICA DISTRIBUTIVA DEL CAPITAL CULTURAL}

El problema de la producción cinematográfica es hoy por encima de cualquier otro el de la distribución... En la sociedad-red, en el modelo de acumulación flexible, toda política audiovisual debe proceder a una reformulación de una lógica de producto a una lógica de mercado, en función lógicamente de una estrategia transnacional y multimedia:

4. Douglas Gomery, «Hacia una nueva economía de los medios», en Archivos de la Filmoteca, Valencia, Junio de 1998, p.161. 
«No existen posibilidades serias de crecimiento de la producción fílmica $e$ inclusive de garantizar su nivel actual - si no se traslada al problema mercados - sean ellos internos, subregionales o regionales, específicamente cinematográficos o audiovisuales en general - el eje de las políticas a diseñar e implementar»(5).

Es necesario por tanto un replanteamiento de perspectiva de la preocupación por el crecimiento productivo a las necesidades de desarrollo de la producción audiovisual. En esta misma dirección apunta en parte el Programa «Medidas para Estimular el Desarrollo de la Industria Audiovisual» (MEDIA) vigente para el período que concluye este año 2000. La formación, el desarrollo de producciones europeas y especialmente el acento sobre la distribución transnacional en el continente de obras audiovisuales propias constituyen los ejes que han venido guiando la acción del Proyecto MEDIA II desde 1996, preocupado por el desarrollo de:

- Redes de cooperación transfronteriza a nivel profesional, entre las asociaciones, los proyectos y agentes de la industria audiovisual de los países europeos.

- Una industria alimentada por la actividad creativa de productores independientes, y de pequeñas y medianas empresas que sean competitivas en el mercado mundial de la información.

- Y la distribución transnacional de programas, que difundan los valores creativos y las identidades culturales de las naciones miembros de la Comunidad.

La iniciativa de este y otros programas públicos en la política audiovisual europea se contradice, sin embargo, en sus propios términos, al esperar el cumplimiento de estos objetivos con la:

- Creación de un mercado europeo de servicios audiovisuales.

- El fomento de la distribución y el marketing.

- Y el equilibrio del mercado y de la industria de la comunicación por el ajuste de la oferta y la demanda audiovisual en los canales de exhibición y distribución comercial.

Desde luego, tal y como advierte Getino, «no se trata (...) de defender el cine desde la óptica de quienes quieren hacer películas, sino desde la visión más amplia y trascendente de comunidades enteras que quieren conservar y recrear simultáneamente junto con sus imágenes la necesaria vitalidad de su imaginario colectivo ${ }^{(6)}$. Pero, aunque este y otros programas específicos de la Unión Europea ponen el acento en las relaciones entre productores, medios audiovisuales y

5. Octavio Getino, «Industria cinematográfica y producción propia. El audiovisual latinoamericano», en Voces y Cclturas, número 13, Barcelona, 1998, p.15.

6. Ibíd., p.10. 
nuevos operadores de telecomunicaciones, dando una visión industrial de lo cinematográfico, en el contexto más amplio del audiovisual, el acento en las estrategias de marketing y comercialización global de la producción cinematográfica, ya iniciada a finales de los ochenta por las productoras estadounidenses, no deja de mostar una contradictoria fe ciega en las fuerzas del mercado que son las que, paradójicamente, están favoreciendo un movimiento regresivo de la industria audiovisual europea en favor de las grandes empresas multimedia norteamericanas. La necesidad de producción y explotación comercial de todo tipo de artículos con cada unidad fílmica, (revistas , juguetes, CD ROM, videos interactivos, libros y merchandasing en general) como condición industrial que cada vez más determina, aún siendo mercado secundario, el modelo de producción cinematográfica ha podido funcionar en casos como «Torrente» de manera relativa, pero siempre dentro del reducido mercado nacional, y reproduciendo además esquemas tópicos poco enriquecedores culturalmente para el imaginario de las identidades regionales dentro y fuera de Europa:

«Las cintas comerciales pueden llegar a convertirse en fuentes de activos multimillonarios y no existe razón alguna para pensar que la tecnología moderna alterará dicha realidad sino que, antes al contrario, contribuirá a reforzar aún más, si cabe, el valor de los éxitos taquilleros que se exportan desde Hollywood. Y, dado que estos éxitos de taquilla se inician en los cines, parece oportuno señalar que un mundo de quinientos canales televisivos sólo servirá paradójicamente, para incrementar el valor de dichos cines» $»^{(7)}$.

Tanto en las salas como en los nuevos canales de comercialización cinematográfica será Hollywood y su industria el más ampliamente beneficiado por esta nueva tendencia. El circuito de distribución comercial de las obras fílmicas sigue una lógica de valorización (exhibición y distribución en salas, pay per view, televisión en abierto, video, cine-clubs,...) dominado por los grandes grupos multimedia. Por ello, la confianza en el mercado al plantear las políticas europeas de apoyo a la producción cinematográfica comunitaria no deja de ser una contradicción en sus términos, pues el mercado no es libre ni competitivo, antes bien aparece atravesado y dominado por grupos oligopólicos que controlan no sólo los tradicionales circuitos de distribución y exhibición en salas, sino también los nuevos espacios de los parques temáticos (Disney, Timer Warner,...), los canales especializados por cable, los grades operadores de telecomunicaciones y por supuesto los medios audiovisuales convencionales.

7. Douglas Gomery, op.cit., p.155. 
Desde 1984, Hollywood viene desarrollando un proceso de reconversión y adaptación de sus estrategias productivas a los nuevos medios y canales de distribución del capital cultural. «El nuevo mundo del video , la informática y la interacción audiovisual depende ya (desde hace más de una década) de conglomerados mediáticos estadounidenses. Además, cuando dentro de una década como máximo la fibra óptica invada nuestros hogares y puestos de trabajo con mas productos de Hollywood y se acreciente la diversificación y el poder de los seis conglomerados mencionados más arriba, éstas acabarán ganando la batalla por el control de los quinientos canales de televisión por cable, de la misma manera que Hollywood se apoderó en un pasado del mercado del videocasete» ${ }^{(8)}$.

El dominio de la producción deriva pues del control de la distribución y exhibición en los que se apoya la posición oligopólica de la industria audiovisual estadounidense tanto en televisión, en la industria del cable y las telecomunicaciones como, en general, en los nuevos canales y tecnologías de exhibición sobre los que Hollywood redimensionó su industria a lo largo de la década de los ochenta.

HBO (Time), American Movies Classics o Turner Network Television son sólo ejemplos del futuro del cine por cable, y del tipo de operadores que coparán a futuro, de continuar primando la actual política liberalizadora, la totalidad de los espacios de distribución cinematográfica, convertidos en meros canales de distribución de las productoras estadounidenses...

\section{ALTERNATIVAS PUBLICAS, DE LO LOCAL A LO GLOBAL}

La búsqueda de alternativas económicas y socioculturales para la producción cinematográfica europea, y específicamente española, debería plantearse, por coherencia, desde una óptica no mercantil ni liberalizadora, sino más bien desde una perspectiva integral de las políticas públicas, basada en las realidades y opciones de los ámbitos local y regional del espacio de integración comunitaria, en la medida también que el desarrollo autodeterminado y en equilibrio de las economías locales depende, como hemos señalado al principio, de las formas de reconocimiento e identificación del imaginario colectivo. El espacio regional, las comunidades e identidades fuertes que conforman Europa, lo andaluz en este caso, es el contexto propicio para el análisis de los problemas de producción y de mercado cinematográfico nacional y del por el momento fracasado proyecto de construcción del Espacio Audiovisual Europeo.

En MEDIA II (1996-2000) se apuntan precisamente algunas de estas ideas, limitadas no obstante por la concepción liberal de la competencia del mercado que rige en los últimos años las políticas públicas del audiovisual en Europa. La distribución de programas andaluces, la creación de una red local, regional y

8. Ibíd., p.163. 
supranacional es, en efecto, necesaria y factible, a condición de una decidida intervención del sector público, de una articulación mixta de los espacios culturales, con predominio de la autorregulación de agentes culturales, organizaciones, profesionales y tercer sector en general, entre el Estado y el Mercado... En otras palabras, es necesario «volver los ojos hacia lo que nos es propio, concentrando los principales esfuerzos, inquietudes y creatividad en el fortalecimiento de cada espacio local y de la región en su conjunto» para hacer viable la diversificación y construcción colectiva del imaginario por las comunidades europeas.

La proyección del cine andaluz depende, en este sentido, si de un futuro estable y culturalmente autónomo se trata, no del poder y competitividad en el mercado, sino de la afirmación de las imágenes colectivas en el imaginario de la comunidad, capaz de abrir un mercado articulado entre lo local y lo global, entre lo nacional y regional-comunitario, en una apuesta por productos audiovisuales «que muevan los sentimientos y las ideas de un espacio sociocultural, bien definido y concreto, como tentativa para proyectarse ulterior o simultáneamente sobre muchos otros espacios» ${ }^{(9)}$.

Para ello, conviene al menos articular tres tipos de medidas, priorizando, en primer lugar, la capacidad pública de intervención en el sector:

A) INICIATIVAS PUBLICAS: Las diferentes instancias y autoridades públicas, supranacionales (Comisión Europea), estatales y comunitarias (CC.AA.) deben procurar al menos:

* Regular jurídicamente las interrelaciones entre los medios y los espacios audiovisuales comunitarios, nacional e internacionalmente. La experiencia demuestra que la desregulación, la liberalización del audiovisual va en menoscabo de la producción cinematográfica autóctona, por el dominio oligopólico del mercado.

* Elaborar políticas de inversión y fomento del sector, potenciando redes de integración tecnológica, procesos de convergencia económico e industrial a través de la coproducción, el intercambio y los acuerdos de multidifusión. Ello implica una política pública más coherente en el conjunto de las industrias culturales y de las telecomunicaciones, que proteja y desarrolle las identidades culturales diferentes, como es el caso de Andalucía.

* Promover, junto a las políticas de subvenciones directas a la producción, sistemas de créditos blandos para la modernización de las empresas audiovisuales y la producción y exhibición de filmes artísticos con destino a las redes de comercialización y los circuitos sociales.

* Implementar una red de centros de recursos audiovisuales para el consumo, la exhibición y el apoyo a la producción a nivel local, creando una red de

9. Getino, op.cit., p.16. 
archivos de imágenes sobre la memoria cinematográfica y audiovisual de Andalucía.

* Desarrollar el Espacio Audiovisual Iberoamericano a través de convenios y acuerdos en la Cumbre de Jefes de Estado y de Gobierno para la adopción de una política integral de coproducciones y de desarrollo de un mercado común del audiovisual, iniciado con la fundación de la Asociación de Televisión Educativa Iberoamericana y hasta la fecha apenas discutido en los foros públicos y encuentros como el Festival de Huelva entre profesionales y autoridades públicas con responsabilidades en la política económica y en materia cultural y educativa.

B) MEDIDAS ECONÓMICAS: Por su parte, las empresas que operan en el sector debieran procurar progresivamente:

* Incrementar las inversiones locales en producción, distribución y exhibición cinematográfica.

* Integrarse en plataformas de colaboración e intercambio, para un aprovechamiento de las sinergias productivas de los sectores cinematrográficos andaluz, los operadores de telecomunicaciones, los medios de comunicación regional y otras industrias culturales.

* Promover acuerdos regionales de producción y distribución con otras regiones del país y de Europa o Latinoamérica, con participación de las instituciones públicas y otros agentes privados, que participen en estas plataformas comunes.

* Modernizar la infraestructura y procesos de producción y distribución cinematográfica.

* Organizar planes y programas de exportación internacional de la propia producción cinematográfica en cooperación con otras empresas o plataformas industriales, de forma asociativa o empresarial.

C) POLITICAS DE FORMACION: Por último, las políticas de la cinematografía local y regional dependerán en el futuro de una nueva educación de la mirada del público y de la formación avanzada y permanente de los profesionales del sector.

La apuesta del futuro del audiovisual andaluz, español y europeo tiene sin duda en las políticas de formación un factor de renovación e impulso creativo que puede ejercer una beneficiosa influencia en la estructura industrial de la cinematografía y el audiovisual comunitario, como bien apunta el programa MEDIA II. Por ello es prioritario considerar, junto a las medidas contempladas por este programa, la necesidad de:

* Invertir en la formación científica y tecnológica de profesionales del audiovisual como tarea estratégica con el fin de formar recursos humanos capaces de crear, innovar e investigar en el desarrollo artístico e industrial del sector. 
* Establecer una renovación de las líneas de estudio sobre la evolución del sector a nivel regional, nacional y global. Pues la consolidación de espacios de investigación y estudio sistemático de la economía de las industrias culturales y del audiovisual para la formación, conocimiento y difusión entre la opinión pública andaluza de los problemas y evolución del sector es todavía una tarea pendiente.

* Desarrollar un programa andaluz de educación audiovisual y de formación en la lectura y producción de imágenes en los ámbitos formal y no formal de la educación, con el fin de facilitar el acceso a amplios sectores de la población andaluza, especialmente de las áreas rurales, al consumo alternativo de cine local y regional, escasa o nulamente accesible a amplios sectores de la población en nuestro territorio.

El objetivo en suma es plantearse el problema de la producción cinematográfica como un problema neurálgico para el futuro de la sociedad andaluza, a partir de una idea distinta de las industrias culturales que la definida por las políticas públicas hoy imperantes en Europa. Como señala Marx, la primera libertad de prensa, el derecho a la comunicación y la cultura consiste básicamente en no ser una industria. Esta pues es la paradoja y tensión contradictoria en la que se mueve la producción audiovisual: una industria... pero también un arte... el de la mirada incandescente de la cultura... Esto es, el arte de la producción del imaginario, de nuestras identidades y representaciones del universo social...

La producción, en fin, de nosotros mismos, de nuestros sueños y aspiraciones colectivas.

Complejo en-red/o sin duda.

\section{Bibliografía:}

- COllins, R. y MURRONI, C.: New Media. New Policies. Media \& Communications Strategies for the Future, Polity Press, Cambridge, 1996.

- COMISION EUROPEA: La industria cinematográfica a examen. Segundo Informe 1997, DGX/C, Bruselas, 1997.

- FERNANDEZ BLANCO, V.: El cine y su público en España, Fundación Autor, Madrid, 1998.

- GUBERN, R. et al.: Historia del cine español, Cátedra, Madrid, 1995.

- HACKETT FISCHER, David: Historians'Fallacies: Toward a Logic of Historical Thought, Harper and Row, Nueva York, 1970.

- MOSCO, V.: The political economy of communication, Sage, Londres, 1996.

- MOWLANA, H.: Global information and World Communication, Sage, Londres, 1997.

- ORTIZ, Renato: Mundializaçao e cultura, Brasiliense, Sao Paulo, 1994.

- QUIROS, Fernando: Estructura Internacional de la Información, Editorial Síntesis, Madrid, 1998. 
- SCHILLER, H.I.: Aviso para navegantes, Icaria, Barcelona, 1996.

- SCHLESINGER, Ph.: «¿Debemos preocuparnos por Norteamérica?. La política cultural y audiovisual de la Unión Europea», en Telos, número 4, FUNDESCO, Madrid, 1995, pp. 17-28.

- SIERRA, Francisco: «Panorama de la Economía de la Información en el Tardocapitalismo», en Revista Razón y Palabra, número 8, ITESM-CEM, México, 1997.

- VOGEL, H.: Entertainment Industry Economics. A Guide for Financial Analysis, Cambridge University Press, 1995.

(Recibido el 15-6-2000, aceptado el 5-9-2000) 